\title{
Numerical Analysis of Temperature Rise during Dynamic Loading for Dissimilar Steel Joint Specimen
}

\author{
Yasuhito Takashima ${ }^{1, a^{*}}$ and Fumiyoshi Minami ${ }^{1, b}$ \\ 1Joining and Welding Research Institute, Osaka University, \\ 11-1, Mihogaoka, Ibaraki, Osaka, 567-0047, JAPAN \\ atakashima@jwri.osaka-u.ac.jp, ${ }^{b}$ minami@jwri.osaka-u.ac.jp
}

\begin{abstract}
Keywords: Adiabatic heating, Dynamic loading, Dissimilar joints, Dynamic finite element analysis, Infrared thermography
\end{abstract}

\begin{abstract}
In this study, dynamic temperature field in a dissimilar steel joint specimen was numerically analyzed by means of three-dimensional explicit finite element analysis. Fully coupled thermal stress analysis was performed by using FE-code Abaqus/Explicit ver. 6.12. It was assumed that $90 \%$ of the plastic work was transferred to heat. Furthermore, dynamic loading tests were conducted with three-point bending specimen extracted from the dissimilar steel joint between a mild steel and a high tensile strength class steel. The specimen included a U-shape notch in the bonded interface. A high-speed infrared camera was used to measure the temperature field near the bonded interface. The temperature field was recorded at a frame rate of $200 \mathrm{~Hz}$ during the dynamic loading test. The numerically calculated temperature field near bonded interface showed reasonable agreement with the temperature field measured by the high-speed infrared thermography. The temperature in the soft steel particularly increased during the dynamic loading. On the other hand, the increase in temperature in the hard steel area was relatively few.
\end{abstract}

\section{Introduction}

Demands of dissimilar steel joints increase in automotive industry. Combination of dissimilar materials produces good balance and harmony among strength, stiffness, ductility and lightweight. Impact strength and toughness of the dissimilar joint are also important against traffic accidents such as collisions and crashes. Under the dynamic loading condition, high-speed straining adiabatically generates heat. The adiabatic heating causes temperature rise in local area. Strength and toughness of steels generally show temperature dependence.

Temperature fields for specimens subjected dynamic loading has been investigated by finite element analysis taking into account adiabatic heating due to plastic dissipation [1,2]. Needleman and Tvergaard [1] states that the temperature increase during dynamic loading is clearly enough to have a noticeable effect on the local stress fields in the fracture process zone for a double edge cracked specimen. The results of their numerical analysis indicated that the large strain near a crack generated a maximum temperature rise of $300^{\circ} \mathrm{C}$. Rossoll et al. [2] had computed for temperature rise in a Charpy specimen of a low-alloy steel by considering fully adiabatic condition. Their results showed the temperature rise of about $200^{\circ} \mathrm{C}$ near the notch root for a specimen deflection of $1 \mathrm{~mm}$.

It is considered that temperature fields in dissimilar steel joints are different from that in similar steel joints because the strength mismatch in dissimilar steel joints produces non-uniform deformation. The authors investigated the effect of strength mismatch on stress fields for the Charpy specimen of dissimilar steel joints [3]. The strength mismatch caused the notch opening stress was elevated by constraint due to hard material. In this study, dynamic temperature fields in the dissimilar steel joint specimen were numerically analyzed by means of three-dimensional (3D) explicit finite element analysis. Furthermore, dynamic loading tests were conducted with threepoint bending specimen extracted from the dissimilar steel joint between a mild steel and a high tensile strength class steel. The temperature field was recorded by high-speed infrared camera. Dynamic temperature fields were discussed by using numerical analysis and observation with infrared camera. 


\section{Numerical Analysis of Temperature Fields during Dynamic Loading for Dissimilar Steel Joints}

Fully coupled thermal stress analysis was performed by using the finite element code Abaqus/Explicit ver. 6.12 in order to analyze dynamic temperature fields in a dissimilar steel joint specimen. Under the impact loading conditions, high-speed straining adiabatically generates heat. In this study, bending velocity was varied from $100 \mathrm{~mm} / \mathrm{s}$ to $10000 \mathrm{~mm} / \mathrm{s}$.

The specimen of dissimilar steel joint employed in the FE analysis is shown in Fig. 1.
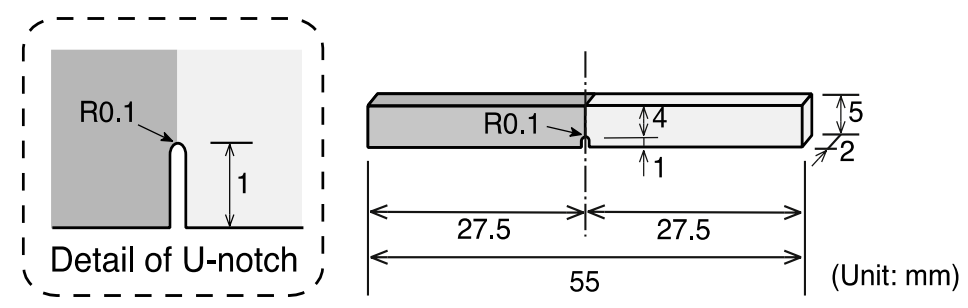

Fig. 1 Configuration of the U-notched specimen for dissimilar steel joint.

The thickness and height of specimen are $2 \mathrm{~mm}$ and $5 \mathrm{~mm}$, respectively. The specimen has a Unotch with a depth of $c=1 \mathrm{~mm}$ and a root radius of $r=0.1 \mathrm{~mm}$. This notch is located in the bonded interface of dissimilar steel joint. The Charpy type striker and anvils were employed for dynamic loading. The 3D mesh of the FE model is shown in Fig. 2. Because of the symmetry of the specimen, only half of it was modeled. Eight-node elements with eight Gaussian integration points were used in the FE analysis; the smallest element near the notch root had dimensions of $0.025 \mathrm{~mm}$ $\times 0.025 \mathrm{~mm} \times 0.1 \mathrm{~mm}$. The total number of elements was 16,442 , and the total number of nodes was 20,684 .

The dynamic explicit analysis procedure was used in this study. This procedure solves the equation of motion for a body by means of the explicit central difference integration rule

$$
\ddot{u}_{i}=\mathbf{M}^{-1} \cdot\left(\mathbf{F}_{i}-\mathbf{I}_{i}\right)
$$

where $\ddot{u}$ is the acceleration vector, $\mathbf{M}$ is the mass matrix, $\mathbf{F}$ is the applied load vector, and $\mathbf{I}$ is the internal force vector. The subscript $i$ refers to the increment number. The time increment used in the explicit analysis was smaller than the stability limit satisfying the Courant-Friedrichs-Lewy condition. This analysis considered the contact of the specimen with the striker and anvil. The global response of impact load to the specimen depends on the contact stiffness between the specimen and striker. In this study, the contact problem was solved using the Hertzian contact theory [3]. The authors validated this method for a mild steel by comparison with experimental results obtained using an instrumented Charpy impact testing machine, which measured the impact load and the load point displacement [4].

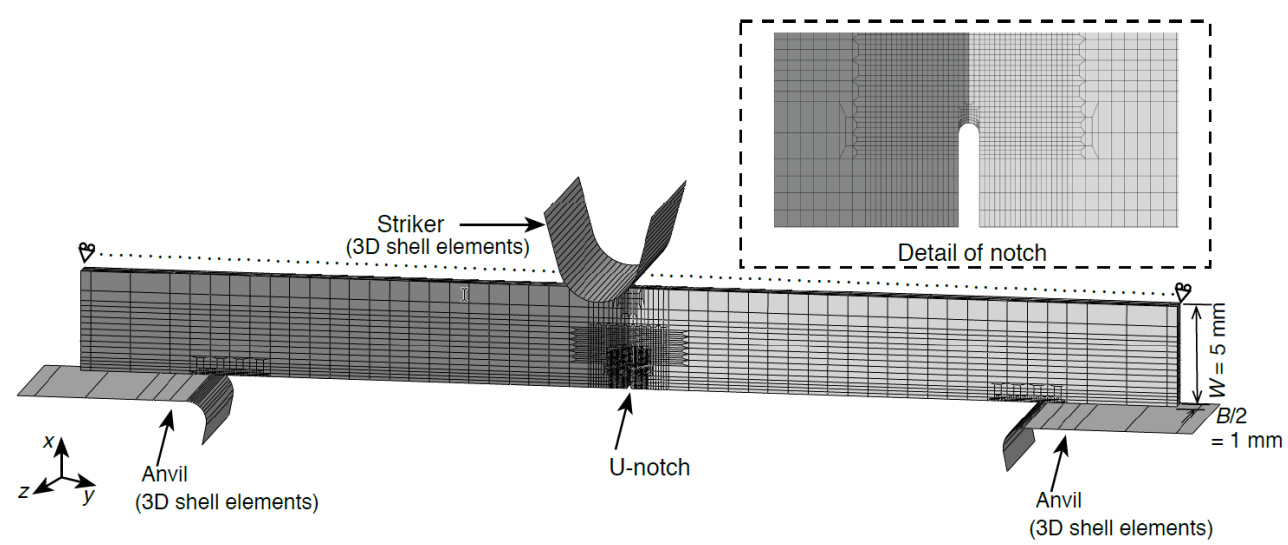

Fig. 2 Mesh division of dissimilar steel joint specimen (1/2 model). 
Adiabatic heating due to plastic dissipation was accounted for this analysis. Fully coupled thermal stress analysis was adopted together with the dynamic explicit analysis. Taylor and Quinney [5] measured the dissipation energy to generate heat for metals and it was about $90 \%$ of total plastic work. In the analysis, it was assumed that $90 \%$ of the plastic work was transferred to heat. The thermal constants used in this analysis are given in Table 1.

Table 1 Thermal constants used in FE analysis.

\begin{tabular}{|c|c|c|c|}
\hline $\begin{array}{c}\text { Specific } \\
\text { heat, } \\
C \\
{[\mathrm{~J} / \mathrm{kg} \cdot \mathrm{K}]}\end{array}$ & $\begin{array}{l}\text { Density, } \rho \\
{\left[\mathrm{kg} / \mathrm{mm}^{3}\right]}\end{array}$ & $\begin{array}{c}\text { Thermal } \\
\text { conductivity, } \\
\lambda[\mathrm{W} / \mathrm{K} \cdot \mathrm{mm}]\end{array}$ & $\begin{array}{l}\text { Coefficient of } \\
\text { linear } \\
\text { expansion, } \alpha_{\mathrm{L}} \\
{[1 / \mathrm{K}]}\end{array}$ \\
\hline $4.69 \times 10^{2}$ & $7.86 \times 10^{-6}$ & $5.18 \times 10^{-2}$ & $1.2 \times 10^{-5}$ \\
\hline
\end{tabular}

The results of this method for the Charpy specimen [6] suggested that the temperature increased in almost all ligament sections of the specimen for absorbed energy of $24 \mathrm{~J}$.

The mechanical properties of steels used for a dissimilar steel joint are listed in Table 2 under static condition at room temperature. This analysis included the effect of the strain rate on the flow stress as well as the increase in temperature during impact loading. The rate-dependent elastic-plastic material behavior of the specimen was considered in the finite element analysis. The effect of the strain rate on the tensile properties was evaluated using the strain rate-

Table 2 Strength and elongation adopted in FE analysis.

\begin{tabular}{|c|c|c|c|}
\hline & $\sigma_{\mathrm{Y}}[\mathrm{MPa}]$ & $\sigma_{\mathrm{T}}[\mathrm{MPa}]$ & $\varepsilon_{\mathrm{T}}[\%]$ \\
\hline Mild steel & 288 & 412 & 22.5 \\
\hline High strength steel & 616 & 788 & 6.1 \\
\hline
\end{tabular}
temperature parameter $R$ proposed by Bennet and Sinclair [7]. The yield stress $\sigma_{\mathrm{Y}}$ and tensile strength $\sigma_{\mathrm{T}}$ are plotted in Fig. 3 with respect to the parameter $R$ used in this analysis. The uniform elongation $\varepsilon_{\mathrm{T}}$ was assumed to be independent of the strain rate and the temperature.

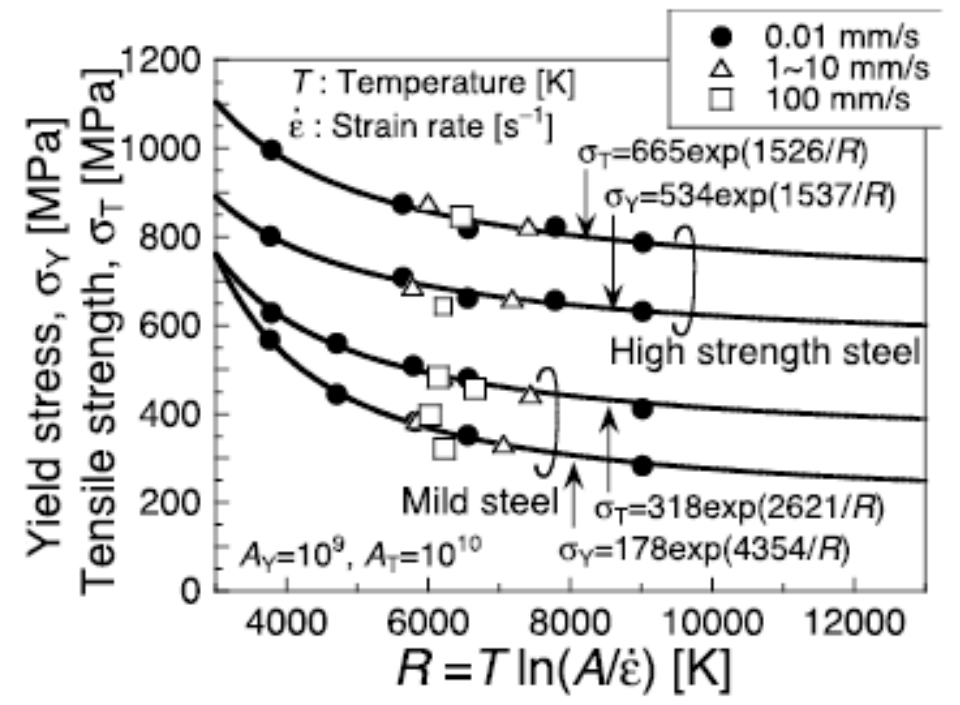

Fig. 3 Yield stress $\sigma_{\mathrm{Y}}$ and tensile strength $\sigma_{\mathrm{T}}$ plotted against strain rate-temperature parameter $R$.

In the analysis, material hardening was modeled based on Swift's power law as

$$
\bar{\sigma}=\sigma_{\mathrm{Y}}\left\{1+\left(\bar{\varepsilon}_{\mathrm{p}} / \alpha\right)^{n}\right\}
$$


where $\overline{\bar{\sigma}}$ and $\bar{\varepsilon}_{\mathrm{p}}$ are the equivalent stress and equivalent plastic strain, respectively; $n$ is the strain hardening exponent; and $\alpha$ is a material constant. According to Eq. (3), $\sigma_{\mathrm{T}}$ and $\varepsilon_{\mathrm{T}}$ are given by

$$
\begin{aligned}
& \sigma_{\mathrm{T}}=\sigma_{\mathrm{Y}} \cdot(n / \alpha)^{n} \cdot \exp (\alpha-n) \\
& \varepsilon_{\mathrm{T}}=\exp (n-\alpha)-1
\end{aligned}
$$

Eqs. (4) and (5) were used to determine the values of $n$ and $\alpha$ from $\sigma_{\mathrm{Y}}, \sigma_{\mathrm{T}}$, and $\varepsilon_{\mathrm{T}}(=22.5 \%$ for a mild steel and $6.1 \%$ for a high strength steel) under various strain rate and temperature conditions.

\section{Measuring of Temperature Fields during Dynamic Loading}

A dynamic loading test was carried out using the dissimilar steel joint specimen. The specimen was extracted from a clad joint [3], which was consisted of a mild steel and a high strength steel. Chemical compositions of these steels are shown in Table 3. The Vickers hardness distribution of the dissimilar steel joint is shown in Fig. 4. The hardness distribution is stepwise near the bonded interface. The hardness ratio of the mild steel and the high strength steel is about 0.5 .

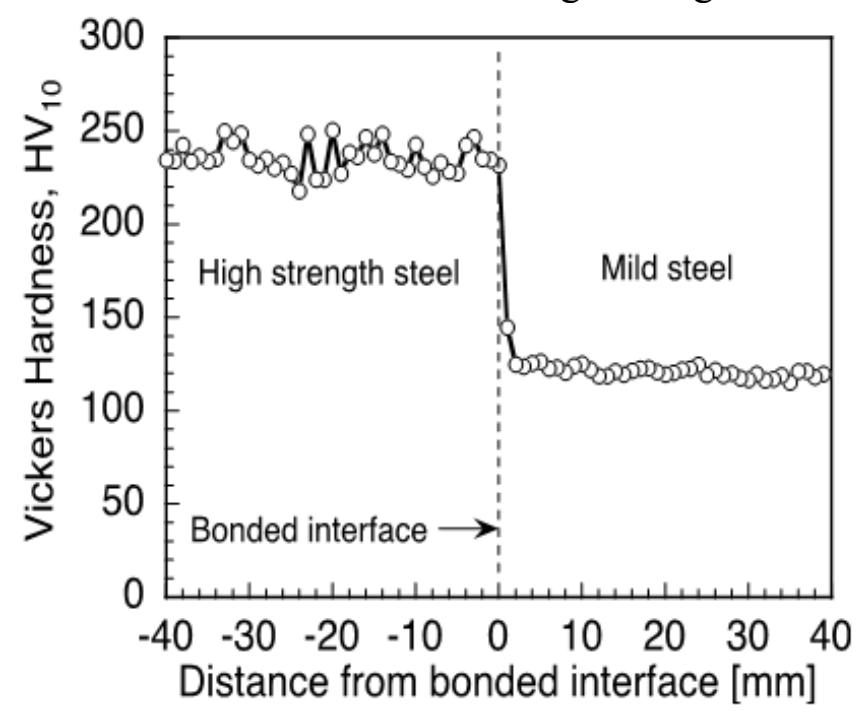

Fig. 4 Vickers hardness distribution of the dissimilar steel clad joint.

An impact testing machine with servo actuator was employed for dynamic test with a crosshead speed of $100 \mathrm{~mm} / \mathrm{s}$. The dynamic test was conducted at room temperature. The specimen temperature was measured by a high-speed infrared thermal camera, FLIR A655sc. The temperature field was recorded at a frame rate of $200 \mathrm{~Hz}$ during the dynamic loading test.

The recorded temperature field is shown in Fig. 5 for a specimen deflection of $0.5 \mathrm{~mm}$. The temperature rise was observed near the bonded interface in the dissimilar steel joint. The temperature distribution is asymmetric around the bonded interface. The result suggested that plastic dissipation in the mild steel part was different from the high strength steel part. The temperature in the mild steel part is higher than that in the high strength steel part. The asymmetrical distribution of temperature rise is a characteristic of the temperature field for dissimilar steel joint specimen subjected dynamic loading. 


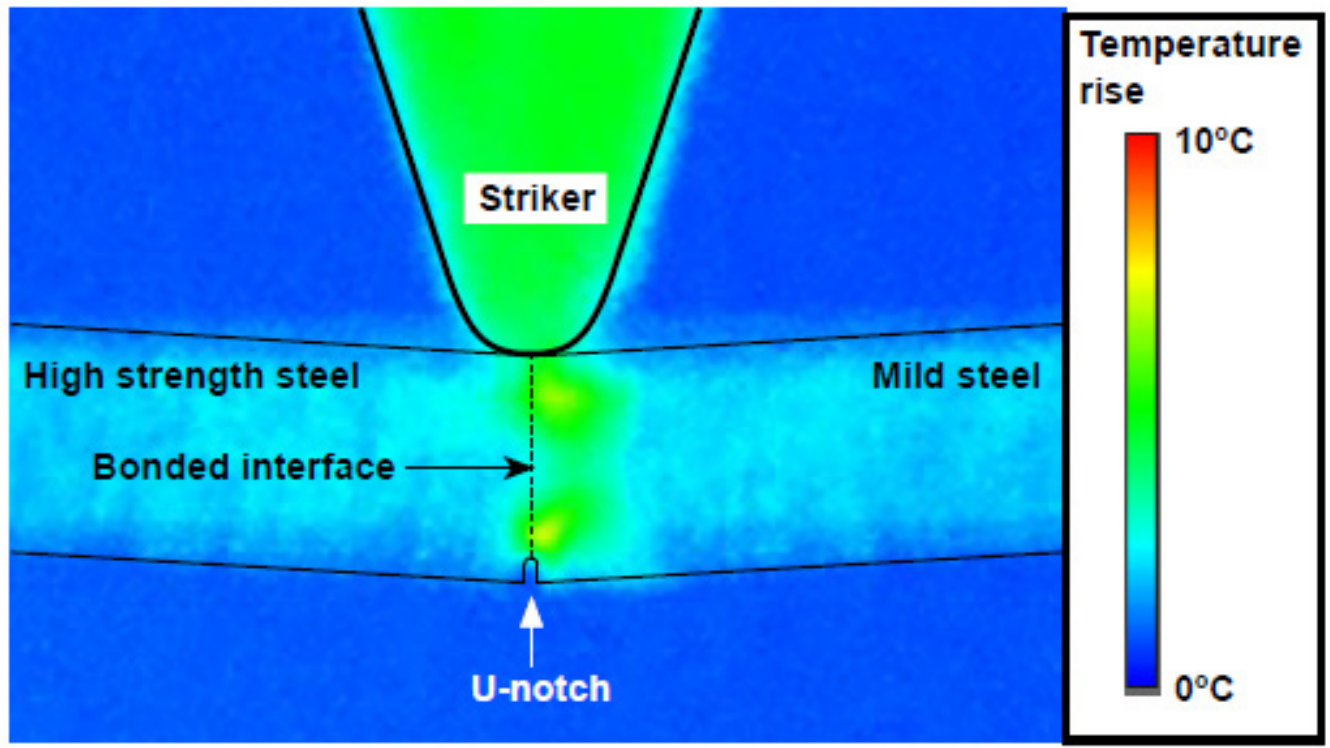

Fig. 5 Temperature fields measured by high-speed IR camera. (specimen deflection of $0.5 \mathrm{~mm}$, striker velocity of $100 \mathrm{~mm} / \mathrm{s}$.

\section{Temperature Fields during Dynamic Loading for Dissimilar Steel Joints Specimen}

The influence of adiabatic heating due to plastic dissipation was investigated for dissimilar steel joints by means of 3D dynamic explicit finite element analysis. The temperature rise near the notch is shown in Fig. 6 for a specimen deflection of $0.5 \mathrm{~mm}$. The computed temperature rise showed reasonable agreement with that measured by the infrared camera. The result indicated that the validity of the numerical analysis of temperature rise during dynamic loading was demonstrated for the dissimilar steel joint specimen.

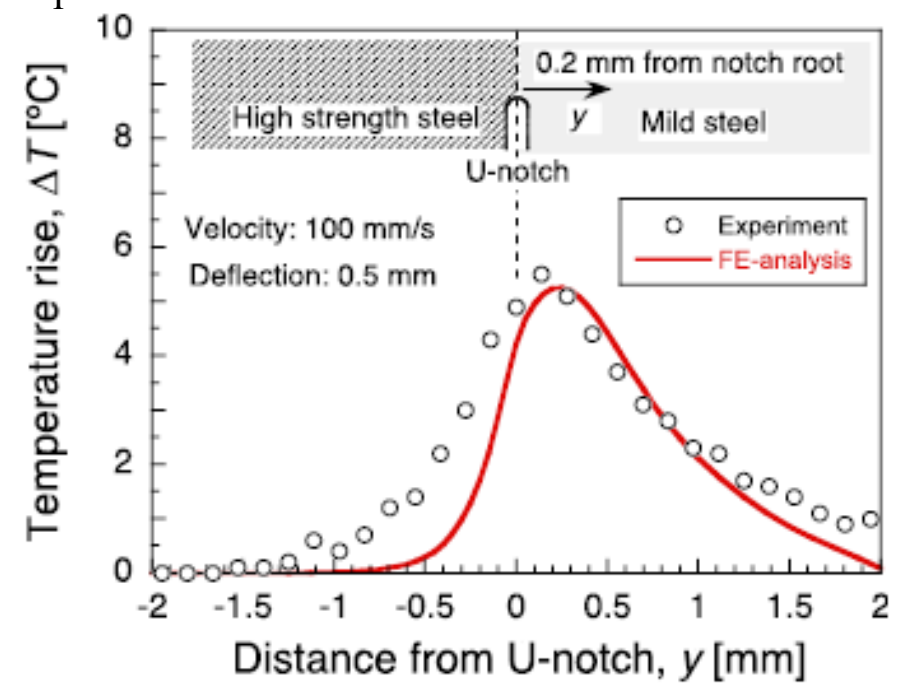

Fig. 6 Comparison of measured temperature rise and computed by dynamic FE analysis.

The computed temperature distribution was asymmetric and the temperature rise in the mild steel part was remarkable compared with the high strength steel part. The asymmetrical distribution of temperature rise was due to a difference of plastic dissipation between the mild steel part and the high strength steel part. The plastic strain was concentrated near the notch and plastic zone expanded to the opposite direction to high strength steel, because the high strength steel can hardly be deformed. The plastic strain energy stored in each part consisting of the mild steel or the high strength steel was calculated. Almost all of the plastic strain energy was absorbed in the mild steel part. The peak temperature was observed in the mild steel part near the bonded interface in the dissimilar steel joint. 
The influence of strength mismatch in the dissimilar steel joint on temperature field was discussed. The distribution of temperature rise near the notch is shown in Fig. 7 for the specimen surface. In the case of the similar steel joint, the temperature distributes symmetrical to the bonded interface. On the other hands, the temperature rise in the mild steel part of the dissimilar steel joint was higher than that of the similar steel joint. The concentration of plastic deformation in the mild steel part of the dissimilar steel joint generated more plastic dissipation.

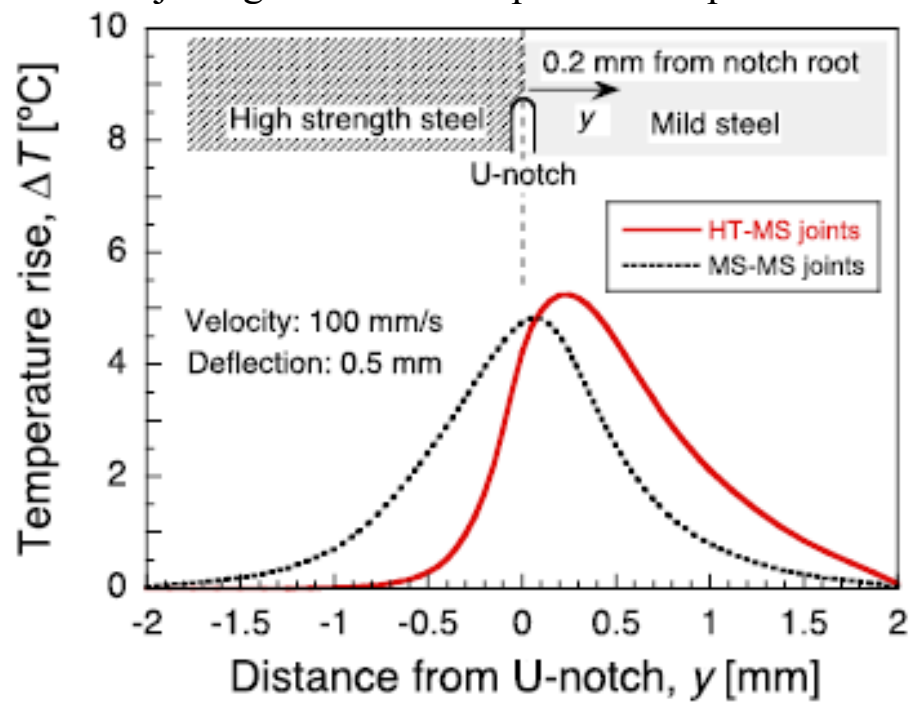

Fig. 7 Influence of strength mismatch in the dissimilar steel joint on temperature fields.

The influence of the striker velocity on the temperature rise was computed. The temperature rise for a specimen deflection of $2 \mathrm{~mm}$ for the velocity of $10000 \mathrm{~mm} / \mathrm{s}$ was compared with the velocity of $100 \mathrm{~mm} / \mathrm{s}$, as shown in Fig. 8. The maximum temperature rise was about $60^{\circ} \mathrm{C}$ for the velocity of $10000 \mathrm{~mm} / \mathrm{s}$. High velocity caused high temperature rise due to plastic dissipation as heat diffusion rate was slower than straining speed. As is shown in Fig. 8, the asymmetrically of the temperature rise was more remarkable with increase in the velocity.

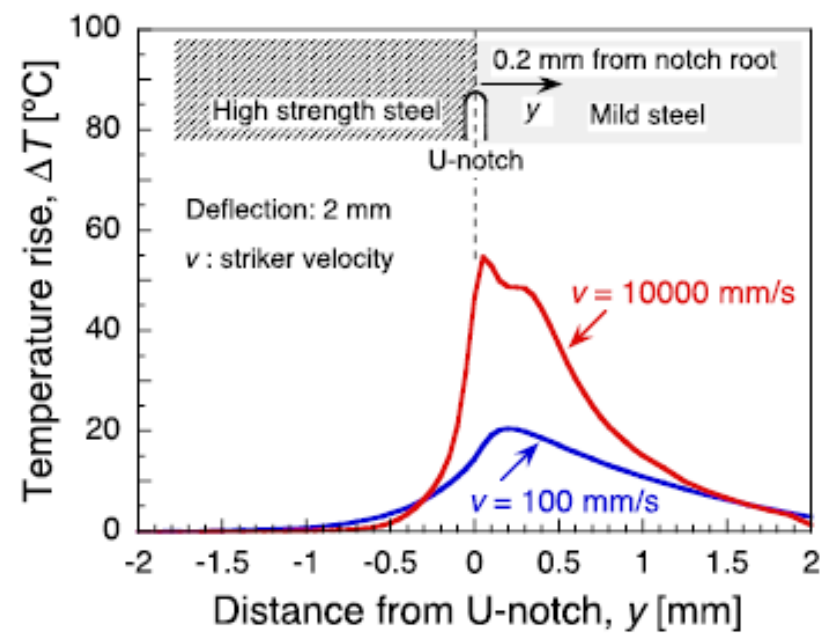

Fig. 8 Distribution of temperature rise near bonded interface in specimen (crosshead speed: $100 \mathrm{~mm} / \mathrm{s}$ and $10000 \mathrm{~mm} / \mathrm{s}$ ).

\section{Summary}

This study numerically simulated the dynamic temperature fields for a dissimilar steel joint specimen. Fully coupled thermal stress analysis was performed by dynamic explicit finite element method taking into account adiabatic heating due to plastic dissipation. The numerically calculated temperature field near bonded interface showed reasonable agreement with the temperature field measured by the high-speed infrared thermography. The temperature in the soft steel particularly 
increased during the dynamic loading. On the other hand, the increase in temperature in the hard steel area was relatively few. The asymmetrical distribution of temperature rise is a characteristic of the temperature field for dissimilar steel joint specimen subjected dynamic loading. The asymmetrically of the temperature rise was more remarkable with increase in the velocity.

\section{Acknowledgment}

This work was supported by JSPS KAKENHI Grant Number JP17K14822.

\section{References}

[1] A. Needleman, V. Tvergaard, An analysis of dynamic, ductile crack growth in a double edge cracked specimen, Int. J. Fracture, 49 (1991) 41-67.

[2] A. Rossoll, C. Berdin, P. Forget, C. Prioul, B. Marini, Mechanical aspects of the Charpy impact test, Nucl. Eng. Des., 188 (1999) 217-229.

[3] Y. Takashima, Y.S. Yamada, T. Handa, S. Igi, K. Oi, F. Minami, Numerical analysis of strength mismatch effect on stress field in Charpy specimen, Weld World. 59 (2015) 433-441.

[4] Y. Takashima, T. Handa, F. Minami, Three-Dimensional Dynamic Explicit Finite Element Analysis of Charpy Impact Test, Mater. Sci. Forum. 879 (2017) 1905-1910.

[5] G.I. Taylor, H. Quinney, The latent energy remaining in a metal after cold working. Proc. of the Royal Society of London, 143 (1934) 307-326.

[6] Y. Takashima, T. Kawabata, S. Yamada, F. Minami, Observation of micro-cracks beneath fracture surface during dynamic crack propagation, Theor. Appl. Fract. Mech. 92 (2017) 178-184.

[7] P.E. Bennett, G.M. Sinclair, Parameter representation of low-temperature yield behavior of body-centered cubic transition metals. Trans. ASME, 88 (1966) 518-524. 